\title{
Chapter 2 \\ The Relationship of Motivation with Achievement in Mathematics
}

\begin{abstract}
Students' motivations and attitudes influence their learning of and performance on assessments of school subjects, including mathematics. Relevant theories (e.g., self-determination, expectancy-value, self-efficacy, self-concept, and achievement goal theory) capture key motivational factors that are important to learning and achievement. The theories and related empirical studies that show how motivation factors relate to performance are comprehensively reviewed in this chapter. Generally, students who demonstrate greater self-efficacy and interest in mathematics, and those who value the subject more highly achieve better outcomes, although the relationships may often be modest. Correlational and experimental evidence for the association of motivation with achievement is presented with reference to longitudinal and cross-cultural comparisons, as well as to findings from international large-scale assessments, such as IEA's Trends in International Mathematics and Science Study (TIMSS). Cluster analysis is one tool that may be used to understand the person-centered conditions that are most strongly associated with specific motivational factors related to TIMSS achievement scores.
\end{abstract}

Keywords Achievement goal theory $\cdot$ Expectancy-value theory $\cdot$ Person-centered approach $\cdot$ Self-concept $\cdot$ Self-determination theory $\cdot$ Self-efficacy $\cdot$ Student motivation theories

\subsection{Introduction to Student Motivation}

\footnotetext{
If there is a cornerstone in the science of human behavior, it must be the field of motivation. Motivational theories ask a fundamental question, namely: what moves a person. They are concerned with the prime force at work in human nature and human culture (Ryan 1998, p. 114).
}

The study of motivation is central to the science of human behavior in general, and Ryan's (1998) statement is also relevant to educational science. By motivation, we mean the reasons, purposes, intentions, goals, feelings, intuitions, values, beliefs, and attitudes that humans use to explain why they do the things they do (Mercier and Sperber 2017). Simply put, "a person who feels no impetus or inspiration to act is thus characterized as unmotivated, whereas someone who is energized or activated toward 
an end is considered motivated" (Ryan and Deci 2000, p. 54). While environmental and genetic factors may shape human behavior, individual motivation contributes to behavior and outcomes.

In educational settings, the study of student motivation is central, because this interacts with educational choices and achievement behavior in important ways (Bandura 1997; Deci and Ryan 1985; Hattie 2009; Wigfield and Eccles 2002). Students need to learn the skills and competencies expected of them and, to do so, they need the will to learn and perform well in educational assessment settings (Eklöf 2010). Learning science has gone further and pointed to the need for students to gain skills, the will to learn, and experience a motivating thrill in learning that enables them to persist when learning becomes difficult (Hattie and Donoghue 2016).

Motivation is not a static characteristic, but malleable, and differs between and within individuals across different domains, activities, and contexts (Ryan and Deci 2000). Some students learn to achieve extrinsic rewards, while others learn for more intrinsic reasons. The strength of these goal motivations can vary across time, according to the context, and by a student's level of maturity, culture, and individual background demographic characteristics. Thus, motivation matters because, unlike societal habitus or genetic inheritance, individuals seem to be able to select from a range of options, as well as monitor the efficacy of motivation and exercise control over their motives.

Investigations into the mechanisms through which motivation and performance interact, and their causal precedence, remain an important area of research (see, e.g., Cerasoli and Ford 2014; Marsh and Craven 2006). Success or failure interacts with motivating beliefs such that certain motivations and actions are reinforced or inhibited in response to outcomes. For example, if self-efficacy judgments are unrealistic because the self-assessment of competence was not accurate (which occurs especially among novices; Brown and Harris 2013), it is likely that such students will lose motivation or reduce the effort required to undertake a task. However, if the self-efficacy rating accurately predicted actual performance, this could reinforce the students' sense of knowing and could lead to appropriate decisions about continued effort in specific learning domains. Consequently, with multiple aligned or misaligned interactions between motivational beliefs (e.g., self-efficacy, interest, or value) and actual performance, students become reinforced in their motivational stance. Of course, the causal ordering in such reciprocal relations is not well-established, as it is difficult to ascertain a true zero-point baseline. Even if the causal ordering of constructs is not clearly established, there is ample evidence that there are links between knowledge, abilities, academic behaviors, and performance on the one hand, and aspects of motivation on the other (Hattie 2009; Robbins et al. 2004).

The exploration of student motivation in schooling contexts has attracted a great deal of research, and motivational constructs have been evaluated in the TIMSS studies of achievement in mathematics and science (Hooper et al. 2017). Despite the large body of research on achievement motivation, there is still much to be learned, not least when it comes to motivational patterns within individuals, across culture, time, and age groups, and how such motivational patterns inform differences 
in achievement distributions across nations and changes in these distributions over time. Identifying information that is potentially hidden in the correlational approach that is usually undertaken in secondary analyses of ILSA data is important; thus, we will begin by briefly describing major frameworks on motivation before examining their relevance to the motivation constructs included in TIMSS questionnaires.

\subsection{Theoretical Approaches to the Study of Motivation}

Motivation, as a latent construct, is not directly observable, thus theoretical framing matters to its measurement. Motivational theories are concerned with understanding what makes people act in motivated ways, and what makes an individual choose the direction and intensity of actions. What then are the more influential motivational theories, and how are they reflected in the measures of motivation used in TIMSS?

With the advent of modern psychology in the late 19th century, interest developed in the possible factors involved in human motivation. Since then, a "myriad" (Gottfried 2009, p. 464) of theories and explanatory frameworks for motivation have evolved. These have stressed inner needs, drives, instincts, and relationships between stimuli, response, and reinforcement as the initiators of motivated behavior. The modern motivational paradigm is dominated by cognitive theories, which claim that individuals' thoughts, beliefs, and emotions together influence motivation (see Schunk et al. 2010; Wigfield and Eccles 2002; Wentzel and Wigfield 2009). While older theories of motivation (Atkinson 1957) often saw motivation as emanating from needs, or a "drive," contemporary theories tend to stress goals as important motivators; this distinction between push (drive) and pull (goal) is significant. Five key theories are relevant in the context of the measurement of motivation in TIMSS.

\subsubsection{Self-determination Theory}

One of the more influential motivational theories is self-determination theory (SDT). In this (macro-)theory, a distinction is made between different types of motivation based on the different kinds of reasons or goals that give rise to motivated action. SDT is concerned with people's inherent growth tendencies and innate psychological needs (i.e., competence, autonomy, and psychological relatedness) that evolve in interaction with the surrounding social context. SDT focuses on the degree to which an individual's behavior is self-motivated and self-determined. Although rather complex in detail (see Ryan and Deci 2002, 2017), a basic distinction is often made between extrinsic and intrinsic motivation (Ryan and Deci 2000).

Extrinsic motivation refers to goals or reasons related to reaching an external reward (e.g., money, praise from others, good grades) or avoiding negative consequences (e.g., embarrassment upon getting a poor test result, or not being allowed to visit a friend unless homework has been completed as expected). 
According to Deci and Ryan (1985), extrinsic motivation can become more or less internalized and is not, as often described, antithetical to intrinsic motivation. In other words, it can be intrinsic to the self to aspire to external rewards. Intrinsic motivation, in contrast, is when an action is performed "for its own sake," without expectation of external rewards. It can concern things such as personal development, enjoyment of exploring that leads to feelings of "internal rewards," reaching personal goals, mental satisfaction, physical well-being, or enjoyment in the moment. The focus can be on the process more than the result, though the result itself may be invisible to external parties. Intrinsic and internalized (self-determined) motivation is often linked to stronger devotion, greater persistence, and deeper processing. In practice, motivated behavior is often guided by both internal and external factors. However, individuals will differ in the balance between internal and external motivations, and the degree of internalization of extrinsically-focused motivating factors may appear to differ even within social contexts.

TIMSS has measured attitudes and motivation towards learning and achieving in mathematics and science from 1995 and onwards (Hooper et al. 2017). However, it is not clear if and how operationalization of SDT into TIMSS survey items has been guided by theory. In the recent assessment frameworks, there was reference to SDT when motivational constructs were described (Hooper et al. 2013, 2017). Enjoyment, confidence, and value for mathematics and science are constructs operationalized and measured in the TIMSS background questionnaires. Inspection of the scales indicates that enjoyment items relate to intrinsic motivation and some value items relate to extrinsic motivation.

\subsubsection{Expectancy-Value Theory}

Previous research has shown that it is possible to interpret the motivational scales used in TIMSS within an expectancy-value framework (Eklöf 2007). The expectancy-value theory (EVT) of achievement motivation originates from the first half of the 20th century (Atkinson 1957; Weiner 1992), but the most widely used expectancy-value model derives from the more recent work of Eccles and Wigfield (Eccles and Wigfield 2002; Wigfield 1994; Wigfield and Eccles 2002). This model focuses on the role of students' expectancies for academic success and their perceived value for academic tasks; it is based on personality, social, and developmental psychology (Pintrich and Schunk 2002). EVT has two core components: an expectancy component that corresponds to the question "Can I do this task?" (namely, student perceptions of their abilities), and a value component that corresponds to the question "Do I want to do this task and why?" The expectancy component in the model refers to the individual's beliefs and judgments about his or her capabilities to do a task and succeed at it, with obvious correspondence with constructs from other theoretical traditions such as self-schemata, self-concept, or self-efficacy. The value component in the model refers to the various reasons individuals have for engaging in a task or not, and the strength of those values. Both of these components have been shown to be important predictors of achievement behavior (Wigfield and Eccles 1992). 
The different value components in the model are attainment value (perceived importance of doing well on a task), intrinsic value (interest/enjoyment in doing a task), utility value (usefulness in terms of the individual's future goals), and cost (perceived amount of effort required for a task). Intrinsic value is conceptually similar to intrinsic interest in SDT (Deci and Ryan 1985), while utility value resembles the extrinsic motivation component in SDT.

Expectancy beliefs, including self-concept, ability perceptions, and expectancy for success, predict actual achievement in terms of grades and performance on standardized tests. Values have been shown to correlate positively with actual achievement, but when both expectancy beliefs and values are used simultaneously to predict achievement, expectancy beliefs remain significant predictors, while values become not significant predictors. However, in terms of intentions to take future courses and actual enrollment in those courses, value beliefs are actually better predictors than expectancy beliefs (Eccles 1983; Meece et al. 1990; Wigfield and Eccles 1992). Confidence and enjoyment for mathematics and science have been measured in TIMSS questionnaires using several items in the past, although more recently, they have been measured as separate, multi-item scales; grade eight students are asked to report how much they value the two subjects.

\subsubsection{Self-efficacy Theory}

Self-efficacy can be understood as the individual's conviction that he or she is capable of successfully performing a given task (Bandura 1997). This is analogous to "Can I do this task?" in the terminology of EVT. Self-efficacy theory is grounded in a larger theoretical framework known as social cognitive theory, which assumes that human achievement depends on interactions between an individual's behaviors, personal factors (e.g., thoughts and behaviors), and environmental conditions. TIMSS does not measure self-efficacy, although we found references to Bandura's work in the theoretical frameworks (e.g., see Hooper et al. 2013).

\subsubsection{Self-concept}

Related to self-efficacy, and not always easy to separate empirically, is the theoretically different and broader construct of self-concept. Self-concept can be defined as an individual's "collective self-perceptions that are formed through experiences with and interpretations of the environment" (Wigfield and Eccles 2002, p. 16). Self-concept then is how individuals perceive and evaluate themselves: questions such as "Who am I?" and "What kind of person am I?" are the foci of self-concept (Hattie 1992). Self-concept is heavily influenced by reinforcements and evaluations by significant others (Shavelson and Bolus 1982) and it is multidimensional in the sense that self-concept differs according to context; an individual's self-concept could differ for mathematics, reading, or academics in general 
(Marsh 1990). Self-concept differs from self-efficacy both in specificity and content (Michaelides 2008); the former focuses on "Who I am," while the latter focuses on "How sure am I that I can do something?" Aspects of self-concept and self-efficacy are also incorporated as parts of other models of motivation, such as EVT. In recent cycles of TIMSS, the measure of student confidence in mathematics and science included items that could be related to aspects of self-concept.

\subsubsection{Achievement Goal Theory}

Achievement goal theory (Ames 1992; Dweck and Leggett 1988; Elliott and Dweck 1988; Pintrich 2000) assumes that students have different reasons for engaging or not engaging in learning and school work. These reasons affect what, how, and why students learn (Patrick et al. 2011) and how they subsequently perform. Typically, two different sets of achievement goals are identified: (1) task and ego goals (Nicholls 1984) or (2) mastery and performance goals (Dweck and Leggett 1988). The primary goal of a mastery-oriented person is the learning and mastery of the task for its own sake (similar to intrinsic motivation in SDT and intrinsic value in EVT). Mastery goals reflect a desire to achieve competence in terms of set criteria or task mastery. They rely on comparisons with the explicit requirements of the task and/or internal comparisons with an individual's past or potential attainment. Performance goals, in contrast, reflect a desire to achieve competence to a degree that is relative to the performance of others. The goal here is to do well and gain the rewards associated with high performance. The desire to attain high performance sometimes leads to strategic behaviors that can involve making learning more difficult for competitors (Murdock et al. 2016). These two goal orientations are associated with different consequences in achievement context, with mastery being associated with higher performance than performance orientation.

\subsection{Measures of Motivation in TIMSS}

TIMSS administers questionnaires to different actors in the school system, including students, school leaders, teachers, and parents. Over the years, the questionnaires have changed, as have the components of motivation that are assessed (see Mullis et al. 2017). As our study aimed to evaluate trends in motivation, we restricted ourselves to measures of motivation that were present in all the TIMSS cycles included in the study. Therefore, we focused on the constructs "Students like learning mathematics," "Students value mathematics," and "Students are confident in mathematics," which have all been operationalized in recent administrations. In the TIMSS frameworks (see, e.g., Hooper et al. 2013, 2017), the construct "Students like learning mathematics" is interpreted as a measure encompassing intrinsic motivation, while "Students value mathematics" is interpreted as a measure comprising items 
related to extrinsic motivation, attainment, and utility value. "Students' confidence in mathematics" is intended as a measure of student self-concept. The deeper theoretical rationale behind these interpretations is not made clear in the frameworks. As described in Sect. 2.2, the frameworks reference SDT, intrinsic and extrinsic motivation, and the work of Deci and Ryan (1985). Self-concept is also briefly mentioned, with reference to Bandura (1997) and the likelihood of successfully completing the school task, as well as to the multi-dimensionality and subjectspecificity of self-concept and the work of Marsh et al. (2000, 2006, 2008, 2013).

The empirical rationale is made clear through evidence that these constructs have shown positive relationships with performance in previous TIMSS studies. Most of the theories we have described could be used as interpretative frameworks for the motivational measures in TIMSS. As we mentioned, motivation is a latent construct and, thus, cannot be observed directly. It follows that constructs such as self-concept and task value do not equal motivation, but are constructs that have been shown to be predictive of achievement motivation (Wigfield and Eccles 2002), which in turn has been shown to be predictive of achievement choices and performance.

The relationship between student motivation and their achievement has been the topic of many reports. In reviewing the literature, we focused on studies performed in the TIMSS context, but also identified other relevant studies.

\subsection{The Relationship Between Motivation and Achievement}

The explanation and prediction of achievement is important to most educational motivation theories (Meece et al. 2006). A vast number of studies have explored components of student motivation and their relationships with performance, and meta-analyses have shown a positive (but often modest) relationship between student motivation (measured in different ways, using different theoretical frameworks) and scholastic achievement (Hattie 2009; Karadag 2017; Lee and Stankov 2018; Osborne et al. 2003). Throughout most of the theoretical and empirical work, the main message is that adaptive and high levels of motivation positively correlate with better learning and achievement. We do not aim to comprehensively review the motivation research field, instead we focus on studies exploring the variables that are assessed in TIMSS and other ILSAs, studies looking at patterns of motivation as children grow older, and a number of studies using person-centered approaches.

Research within the EVT framework suggests that mathematics and science achievement are positively associated with young peoples' values and self-concepts (Casey et al. 1997; Frome and Eccles 1998; Wigfield et al. 1991). In the TIMSS context, the self-concept measure has received particular attention from researchers. A positive self-concept has been shown to be positively related to achievement in TIMSS (Eklöf 2008; Shen and Pedulla 2000), and "results from six previous TIMSS cycles have shown a strong relationship between students' academic selfconcepts and their achievement" (Hooper et al. 2017, p. 72). The relation between 
perceived task value and performance is often less pronounced, but in the TIMSS documentation, it is stated that "TIMSS results have consistently shown a strong relationship between students valuing the subject and their achievement" (Hooper et al. 2017, p. 72; see also Mullis et al. 2004). Similar findings have been reported for TIMSS science (Papanastasiou and Zembylas 2004) and TIMSS mathematics (Patterson et al. 2003). Conversely, researchers have reported only weak relationships between the valuing mathematics scale and mathematics score for some education systems participating in TIMSS (Eklöf 2008; Grønmo et al. 2004; Thomson and Fleming 2004), in particular when other variables have been accounted for in regression models. Multinational analyses from TIMSS and PISA have found rather weak relationships between valuing the subject and achievement (Lee and Stankov 2018; Marsh et al. 2006, 2013).

\subsection{Self-reported Ratings of Motivation Across Education Systems}

Despite some mixed evidence regarding the strength of the relationship between student motivation and student achievement within education systems participating in ILSAs, the relationship between the self-report measures of motivation and student performance is usually positive. However, at the between-country level these relationships are often non-significant or even negative (Artelt 2005; Shen and Pedulla 2000). This seemingly paradoxical finding has been consistently reported in analyses of assessment data. For example, students in poorly-performing education systems often report a positive self-concept in school subjects, while students in the highest-performing education systems often report a low self-concept. Herbert Marsh proposed a "big-fish-little-pond-effect" (or internal versus external frame of reference) to understand this phenomenon (Marsh 1987; Marsh et al. 2000, 2008).

A six-nation study using TIMSS 1995 data showed large variation between education systems in terms of reports of liking mathematics and self-concept (Boe et al. 1999). Within countries, motivational factors had differing effects on performance but, in all countries, self-concept was a strong predictor of performance. Liking mathematics and science was also positively related to performance, but, when self-concept was added to the model, the effect of liking the subject disappeared in some education systems. It was concluded that liking mathematics is more likely to be a function of a positive mathematics self-concept than the reverse. Even if modest in their effects on performance, highly positive attitudes towards mathematics and science can make a substantial change to students' learning and achievement (Boe et al. 1999).

Differing motivational ratings between students from different cultures and countries can also be due to differences in response patterns. There appear to be cultural differences in how students treat the response scales (e.g., extreme or midpoint responding) and those seem to relate to cultural values and affluence (He et al. 2014; Shulruf et al. 2011). For example, within New Zealand's national 
Assessment Tools for Teaching and Learning test norming of reading, writing, and mathematics, the relationship of liking and self-efficacy to achievement was statistically non-significant for two minority ethnic groups (i.e., the Pasifika and Māori) while it was positive for majority Pākeha and minority Asian groups ('Otunuku and Brown 2007). Survey items are vulnerable to adaptations, and, even if appropriate, terms and labels might have different meanings to different people. Studies using TIMSS 2011 data have shown that negatively worded attitude items were associated with response bias that differed across countries (Michaelides 2019; Tee and Subramaniam 2018), a result that is consistently reported in the wider literature (see, e.g., Brown 2004).

\subsection{Self-reported Ratings of Motivation Across Ages}

Developmental changes in motivation in terms of expectancies and values have been rather extensively studied by Eccles and Wigfield and their colleagues (Eccles et al. 1997; Simpkins et al. 2006; Wigfield et al. 1991). These studies indicate that the mean level of self-perceptions of ability decreases as children move into adolescence. At the same time, the accuracy of self-perceptions seems to improve with age, partly because students base their self-perceptions on their interaction with their environment according to this social-cognitive perspective. Having fewer instances to relate their ability to objective criteria, younger student self-perceptions are less accurate; a widely reported phenomenon in studies of student self-assessment (Brown and Harris 2013). Perceptions of task value seem to follow the same developmental pattern. Thus, research has shown that younger children are more positive in terms of self-concept, liking, and valuing the subject than older students. This seems to be true also in the TIMSS context (Eklöf and Costa 2018).

Intrinsic motivation in mathematics has been found to have the greatest decline among school subjects from childhood to adolescence (Gottfried et al. 2001); interest and competency perceptions in mathematics have also been found to decline as students transition from primary to secondary education (Fredericks and Eccles 2002). Indeed, in a New Zealand cross-sectional study of student attitudes towards mathematics, the influence of liking a subject to achievement in that subject shifted from statistically non-significant among elementary school students to becoming negative among high school students, whereas self-efficacy was consistently a positive predictor in both samples (Winheller et al. 2013). Longitudinal investigations have supported the idea that achievement is related to the decline of mathematics motivation (Gottfried et al. 2007). As students gain more experience with a subject and realize their strengths and weaknesses relative to objective performance information, their interest and enjoyment on the whole is expected to decline. For example, in a small, two-year longitudinal study of American high school student attitudes and cheating behaviors, performance goals and attainment values declined by trivial amounts $(|d|<0.10)$ and attainment values had a weaker influence on grade 
point average at the second time point $(\beta=0.18)$ than at the beginning of the study ( $\beta=0.35$ ) (Stephens and Brown 2013), demonstrating autoregressive characteristics of the motivational belief upon achievement.

\subsection{Another Approach to Studying the Motivation- Achievement Relationship}

Variable-centered approaches drawing on the linear model and using correlation and regression techniques are typically encountered in studies on the relationships between motivational variables and educational outcomes. A less common and complementary approach is to search for meaningful groups of individuals within a sample, groups that share similar profiles. We opted to use a person-centered approach (Loken and Molenaar 2008) as an alternative way of uncovering motivational and affective student profiles. The individual student constitutes the unit of analysis in this mode of research.

A number of studies have investigated motivational profiles of students in other contexts using a person-oriented approach, and valuable information can be revealed by this less traditional method. Motivational profiles can be homogeneous (i.e., consistently high, medium, or low on all dimensions) or heterogeneous. For instance, in the context of second language learning, there were homogeneous as well as heterogeneous clusters, that were characterized, for example, by students who had a positive attitude toward learning a second language but did not find it relevant to their future professional life (Csizér and Dörnyei 2005). A cluster analysis of achievement goal orientation variables with elementary school students (Meece and Holt 1993) revealed distinct groups with higher achievement outcomes when mastery goals were highly endorsed compared to other groups with different levels of goal orientations. Ratelle et al. (2007) reported distinct groups of high-school students with varying levels of autonomous, controlled, and amotivated regulation, which differed in their academic achievement. They also reported different groupings with a college sample, indicating that the context and/or developmental factors seem to matter.

The volatility of motivational profiles was reported even within the duration of a single course using a sample of engineering students (Dillon and Stolk 2012), and Bråten and Olaussen (2005) noted changing levels of motivation within an academic year in clusters of nursing and business administration students. In contrast, student clusters based on achievement goal orientation measures were found to be relatively stable across time in lower- and upper-school students (Tuominen-Soini et al. 2011). Baker and Wigfield (1999) applied cluster analysis to multiple reading motivation variables and extracted seven distinct clusters of students that differed in their reading activity but were less variable in their reading achievement. They concluded that, rather than thinking of children as either high or low in motivation, it was important to understand that many children have a mixture of motivational characteristics. Thus, the empirical literature seems to support the view that motivation is state-like, in that it is dynamic in response to context and is not necessarily homogenous within people across time or context. 
Cluster analysis has been applied to the PISA data to explore student profiles of interests in science issues (Olsen and Lie 2011), and school engagement in Finland (Linnakylä and Malin 2008). In our review of the literature, we were unable to identify any other studies related to motivation that used a person-centered approach to analyze ILSA data; applying this method to the TIMSS data should thus provide novel insights.

\section{References}

Ames, C. (1992). Classrooms: Goals, structures, and student motivation. Journal of Educational Psychology, 84(3), 261-271.

Artelt, C. (2005). Cross-cultural approaches to measuring motivation. Educational Assessment, 10(3), 231-255.

Atkinson, J. W. (1957). Motivational determinants of risk-taking behaviour. Psychological Review, 64(6), 359-372.

Baker, L., \& Wigfield, A. (1999). Dimensions of children's motivation for reading and their relations to reading activity and reading achievement. Reading Research Quarterly, 34(4), 452-477.

Bandura, A. (1997). Self-efficacy: The exercise of control. New York, NY: W. H. Freeman and Company.

Boe, E. E., Turner, H. M., May, H., Leow, C., \& Barkanic, G. (1999). The role of student attitudes and beliefs about mathematics and science learning in academic achievement: Evidence from TIMSS for six nations. CRESP Data Analysis Report. Nashville, TN: Consortium for Risk Evaluation with Stakeholder Participation. Retrieved from http://repository.upenn.edu/gse_pubs/413.

Bråten, I., \& Olaussen, B. S. (2005). Profiling individual differences in student motivation: A longitudinal cluster-analytic study in different academic contexts. Contemporary Educational Psychology, 30(3), 359-396.

Brown, G. T. L. (2004). Measuring attitude with positively packed self-report ratings: Comparison of agreement and frequency scales. Psychological Reports, 94(3), 1015-1024.

Brown, G. T. L., \& Harris, L. R. (2013). Student self-assessment. In J. H. McMillan (Ed.), The SAGE handbook of research on classroom assessment (pp. 367-393). Thousand Oaks, CA: Sage.

Casey, M. B., Nuttall, R. L., \& Pezaris, E. (1997). Mediators of gender differences in mathematics college entrance test scores: A comparison of spatial skills with internalized beliefs and anxieties. Developmental Psychology, 33(4), 669-680.

Cerasoli, C. P., \& Ford, M. T. (2014). Intrinsic motivation, performance, and the mediating role of mastery goal orientation: A test of self-determination theory. Journal of Psychology, 148(3), 267-286.

Csizér, K., \& Dörnyei, Z. (2005). Language learners' motivational profiles and their motivated learning behavior. Language Learning, 55(4), 613-659.

Deci, E. L., \& Ryan, R. M. (1985). Intrinsic motivation and self-determination in human behavior. New York, NY: Plenum Press.

Dillon, A., \& Stolk, J. (2012). The students are unstable! Cluster analysis of motivation and early implications for educational research and practice. 2012 Frontiers in Education Conference Proceedings. Piscataway, NJ: IEEE. Retrieved from https://ieeexplore.ieee.org/ document/6462485/authors.

Dweck, C. S., \& Leggett, E. L. (1988). A social-cognitive approach to motivation and personality. Psychological Review, 95(2), 256-273.

Eccles, J. (1983). Expectancies, values and academic behaviors. In J. T. Spence (Ed.), Achievement and achievement motives: Psychological and sociological approaches (pp. 75-146). San Francisco, CA: Freeman. 
Eccles, J. S., \& Wigfield, A. (2002). Motivational beliefs, values, and goals. Annual Review of Psychology, 53, 109-132.

Eccles, J. S., Lord, S. E., Roeser, R. W., Barber, B. L., \& Jozefowicz, D. (1997). The association of school transitions in early adolescence with developmental trajectories through high school. In J. Schulenberg, J. L. Maggs, \& K. Hurrelmann (Eds.), Health risks and developmental transitions during adolescence (pp. 283-320). New York, NY: Cambridge University Press.

Eklöf, H. (2007). Self-concept and valuing of mathematics in TIMSS 2003: Scale structure and relation to performance in a Swedish setting. Scandinavian Journal of Educational Research, 51(3), 297-313.

Eklöf, H. (2008). Test-taking motivation on low-stakes tests: A Swedish TIMSS example. In M. von Davier, \& D. Hastedt (Eds.), Issues and methodologies in large-scale assessments, IERI Monograph Series, Vol. 1. Hamburg, Germany: IEA-ETS Research Institute. Retrieved from http://www.ierinstitute.org/dissemination-area.html.

Eklöf, H. (2010). Skill and will: Test-taking motivation and assessment quality. Assessment in Education: Principles, Policy and Practice, 17(4), 345-356.

Eklöf, H., \& Costa, D. R. (2018). Test-taking motivation in Swedish TIMSS and TIMSS Advanced: Findings across cohorts and over time. Paper presented at the 2018 Annual Meeting of the National Council for Measurement in Education, New York, NY, April 12-16.

Elliott, E. S., \& Dweck, C. S. (1988). Goals: An approach to motivation and achievement. Journal of Personality and Social Psychology, 54(1), 5-12.

Fredricks, J. A., \& Eccles, J. S. (2002). Children's competence and value beliefs from childhood through adolescence: growth trajectories in two male-sex-typed domains. Developmental Psychology, 38(4), 519-533.

Frome, P. M., \& Eccles, J. S. (1998). Parents' influence on children's achievement-related perceptions. Journal of Personality and Social Psychology, 74(2), 435-452.

Gottfried, A. E. (2009). Commentary: The role of environment in contextual and social influences on motivation: Generalities, specificities, and causality. In K. R. Wentzel, \& A. Wigfield (Eds.), Handbook of motivation in school (pp. 463-476). New York, NY: Routledge.

Gottfried, A. E., Fleming, J. S., \& Gottfried, A. W. (2001). Continuity of academic intrinsic motivation from childhood through late adolescence: A longitudinal study. Journal of Educational Psychology, 93(1), 3-13.

Gottfried, A. E., Marcoulides, G. A., Gottfried, A. W., Oliver, P. H., \& Guerin, D. W. (2007). Multivariate latent change modeling of developmental decline in academic intrinsic math motivation and achievement: Childhood through adolescence. International Journal of Behavioral Development, 31(4), 317-327.

Grønmo, L. S., Bergern, O. K., Kjaernsli, M., Lie, S., \& Turmo, A. (2004). Hva i all Verden har skjedd i realfagena: Norske elevers prestasjoner i matematikk og naturfag i TIMSS 2003 [What on earth has happened in the mathematics and science subjects: Norwegian students' achievement in mathematics and science in TIMSS 2003; in Norwegian]. Oslo, Norway: Oslo University, Department of Teacher Education and School Development.

Hattie, J. A. C. (1992). Self-concept. Hillsdale, NJ: LEA.

Hattie, J. A. C. (2009). Visible learning: A synthesis of over 800 meta-analyses relating to achievement. London, UK: Routledge.

Hattie, J. A. C., \& Donoghue, G. M. (2016). Learning strategies: a synthesis and conceptual model. npj Science Of Learning, 1, 16013. Retrieved from http://www.nature.com/articles/ npjscilearn201613.

He, J., Dominguez Espinosa, A., Poortinga, Y. H., \& Van de Vijver, F. J. R. (2014). Acquiescent and socially desirable response styles in cross-cultural value surveys. In L. T. B. Jackson, D. Meiring, F. J. R. Van de Vijver, E. Idemudia, \& W. K. Gabrenya Jr (Eds.), Toward sustainable development through nurturing diversity (pp. 98-111). Melbourne, FL: International Association for CrossCultural Psychology. Retrieved from http://www.iaccp.org/sites/default/files/stellenbosch_pdf/ He.pdf. 
Hooper, M., Mullis, I. V. S., \& Martin, M. O. (2013). TIMSS 2015 context questionnaire framework. In I. V. S. Mullis, \& M. O. Martin (Eds.), TIMSS 2015 assessment frameworks (pp. 61-82). Chestnut Hill, MA: TIMSS \& PIRLS International Study Center, Boston College.

Hooper, M., Mullis, I. V. S., Martin, M. O., \& Fishbein, B. (2017). TIMSS 2019 context questionnaire framework. In I. V. S. Mullis, \& M. O. Martin (Eds.), TIMSS 2019 assessment frameworks (pp. 57-78). Chestnut Hill, MA: TIMSS \& PIRLS International Study Center, Boston College. Retrieved from: http://timssandpirls.bc.edu/timss2019/frameworks/.

Karadag, E. (Ed.). (2017). The factors effecting student achievement: Meta-analysis of empirical studies. Cham, Switzerland: Springer International Publishing. Retrieved from https://www. springer.com/gp/book/9783319560823.

Lee, J., \& Stankov, L. (2018). Non-cognitive predictors of academic achievement: Evidence from TIMSS and PISA. Learning and Individual Differences, 65, 50-64.

Linnakylä, P., \& Malin, A. (2008). Finnish students' school engagement profiles in the light of PISA 2003. Scandinavian Journal of Educational Research, 52(6), 583-602.

Loken, E., \& Molenaar, P. (2008). Categories of continua? The correspondence between mixture models and factor models. In G. R. Hancock, \& K. M. Samuelsen (Eds.), Advances in latent variable mixture models (pp. 277-297). Charlotte, NC: Information Age.

Marsh, H. W. (1987). The big-fish-little-pond effect on academic self-concept. Journal of Educational Psychology, 79(3), 280-295.

Marsh, H. W. (1990). The structure of academic self-concept: The Marsh/Shavelson model. Journal of Educational Psychology, 82(4), 623-636.

Marsh, H. W., Abduljabbar, A. S., Abu-Hilal, M. M., Morin, A. J., Abdelfattah, F., Leung, K. C.,... \& Parker, P. (2013). Factorial, convergent, and discriminant validity of TIMSS math and science motivation measures: A comparison of Arab and Anglo-Saxon countries. Journal of Educational Psychology, 105(1), 108-128.

Marsh, H. W., \& Craven, R. G. (2006). Reciprocal effects of self-concept and performance from a multidimensional perspective: Beyond seductive pleasure and unidimensional perspectives. Perspectives on Psychological Science, 1(2), 133-163.

Marsh, H. W., Hau, K. T., Artelt, C., Baumert, J., \& Peschar, J. L. (2006). OECD's brief selfreport measure of educational psychology's most useful affective constructs: Cross-cultural, psychometric comparisons across 25 countries. International Journal of Testing, 6(4), 311-360.

Marsh, H. W., Kong, C. K., \& Hau, K. T. (2000). Longitudinal multilevel models of the big-fishlittle-pond effect on academic self-concept: Counterbalancing contrast and reflected-glory effects in Hong Kong schools. Journal of Personality and Social Psychology, 78(2), 337-349.

Marsh, H. W., Seaton, M., Trautwein, U., Lüdtke, O., Hau, K. T., O’Mara, A. J., \& Craven, R. G. (2008). The big-fish-little-pond-effect stands up to critical scrutiny: Implications for theory, methodology, and future research. Educational Psychology Review, 20(3), 319-350.

Meece, J. L., \& Holt, K. (1993). A pattern analysis of students' achievement goals. Journal of Educational Psychology, 85(4), 582-590.

Meece, J. L., Anderman, E. M., \& Anderman, L. H. (2006). Classroom goal structure, student motivation, and academic achievement. Annual Review of Psychology, 57, 487-503.

Meece, J. L., Wigfield, A., \& Eccles, J. S. (1990). Predictors of math anxiety and its influence on young adolescents' course enrollment intentions and performance in mathematics. Journal of Educational Psychology, 82(1), 68-81.

Mercier, H., \& Sperber, D. (2017). The enigma of reason. Cambridge, MA: Harvard University Press.

Michaelides, M. P. (2008). Emerging themes from early research on self-efficacy beliefs in school mathematics. Electronic Journal of Research in Educational Psychology, 6(1), 219-234.

Michaelides, M. P. (2019). Negative keying effects in the factor structure of TIMSS 2011 motivation scales and associations with reading achievement. Applied Measurement in Education (in press).

Mullis, I. V. S., Martin, M. O., Gonzales, E. J., \& Chrostowski, S. J. (2004). TIMSS 2003 international mathematics report: Findings from IEA's Trends in International Mathematics and Science Study at the fourth and eighth grades. Chestnut Hill, MA: TIMSS \& PIRLS International Study Center, Boston College. 
Mullis, I. V. S., Martin, M. O., \& Hooper, M. (2017). Measuring changing educational contexts in a changing world: Evolution of the TIMSS and PIRLS questionnaires. In M. Rosén, K. Y. Hansen, \& U. Wolff (Eds.), Cognitive abilities and educational outcomes: A festschrift in honour of Jan-Eric Gustafsson (pp. 207-222). Cham, Switzerland: Springer International Publishing.

Murdock, T. B., Stephens, J. M., \& Groteweil, M. M. (2016). Student dishonesty in the face of assessment: Who, why, and what we can do about it. In G. T. L. Brown, \& L. R. Harris (Eds.), Handbook of human and social conditions in assessment (pp. 186-203). New York, NY: Routledge.

Nicholls, J. G. (1984). Achievement motivation: Conceptions of ability, subjective experience, task choice, and performance. Psychological Review, 91(3), 328-346.

Olsen, R. V., \& Lie, S. (2011). Profiles of students' interest in science issues around the world: Analysis of data from PISA 2006. International Journal of Science Education, 33(1), 97-120.

Osborne, J., Simon, S., \& Collins, S. (2003). Attitudes towards science: A review of the literature and its implications. International Journal of Science Education, 25(9), 1049-1079.

'Otunuku, M., \& Brown, G. T. L. (2007). Tongan students' attitudes towards their subjects in New Zealand relative to their academic achievement. Asia Pacific Education Review, 8(1), 117-128.

Papanastasiou, E. C., \& Zembylas, M. (2004). Differential effects of science attitudes and science achievement in Australia, Cyprus, and the USA. International Journal of Science Education, 26(3), 259-280.

Patrick, H., Kaplan, A., \& Ryan, A. M. (2011). Positive classroom motivational environments: Convergence between mastery goal structure and classroom social climate. Journal of Educational Psychology, 103(2), 367-382.

Patterson, M., Perry, E., Decker, C., Eckert, R., Klaus, S., Wendling, L., \& Papanastasiou, E. C. (2003). Factors associated with high school mathematics performance in the United States. Studies in Educational Evaluation, 29(2), 91-108.

Pintrich, P. R. (2000). The role of goal orientation in self-regulated learning. In M. Boekaerts, P. R. Pintrich, \& M. Ziedner (Eds.), Handbook of self-regulation (pp. 451-502). London, UK: Academic Press.

Pintrich, P. R., \& Schunk, D. H. (2002). Motivation in education: Theory, research, and applications (Second ed.). New Jersey, NJ: Merril Prentice Hall.

Ratelle, C. F., Guay, F., Vallerand, R. J., Larose, S., \& Senécal, C. (2007). Autonomous, controlled, and amotivated types of academic motivation: A person-oriented analysis. Journal of Educational Psychology, 99(4), 734-746.

Robbins, S. B., Lauver, K., Le, H., Davis, D., Langley, R., \& Carlstrom, A. (2004). Do psychosocial and study skill factors predict college outcomes? A meta-analysis. Psychological Bulletin, 130(2), 261-288.

Ryan, R. M. (1998). Commentary: Human psychological needs and the issues of volition, control, and outcome focus. In J. Heckhausen, \& C. S. Dweck (Eds.), Motivation and self-regulation across the life span (pp. 114-133). New York, NY: Cambridge University Press.

Ryan, R. M., \& Deci, E. L. (Eds.). (2002). Self-determination theory and the facilitation of intrinsic motivation, social development, and well-being. American Psychologist, 55, 68-78.

Ryan, R. M., \& Deci, E. L. (2000). Intrinsic and extrinsic motivation: Classic definitions and new directions. Contemporary Educational Psychology, 25, 54-67.

Ryan, R. M., \& Deci, E. L. (2017). Self-determination theory: Basic psychological needs in motivation, development, and wellness. New York, NY: Guilford Press.

Schunk, D. H., Pintrich, P. R., \& Meece, J. L. (2010). Motivation in education: Theory, research, and applications (Third ed.). London, UK: Pearson Education.

Shavelson, R. J., \& Bolus, R. (1982). Self concept: The interplay of theory and methods. Journal of Educational Psychology, 74(1), 3-17.

Shen, C., \& Pedulla, J. J. (2000). The relationship between students' achievement and their selfperceptions of competence and rigour of mathematics and science: A cross-national analysis. Assessment in Education: Principles, Policy and Practice, 7(2), 237-253. 
Shulruf, B., Hattie, J., \& Dixon, R. (2011). Intertwinement of individualist and collectivist attributes and response sets. Journal of Social, Evolutionary, and Cultural Psychology, 5(1), 51-65.

Simpkins, S. D., Davis-Kean, P. E., \& Eccles, J. S. (2006). Math and science motivation: A longitudinal examination of the links between choices and beliefs. Developmental Psychology, 42(1), 70-83.

Stephens, J. M., \& Brown, G. T. L. (2013). Continuity and change: A longitudinal study of student motivation, misconduct and achievement during high school. Paper presented at the Social Psychology of the Classroom International Conference, Auckland, New Zealand, July 15-18.

Tee, O. P., \& Subramaniam, R. (2018). Comparative study of middle school students' attitudes towards science: Rasch analysis of entire TIMSS 2011 attitudinal data for England, Singapore and the USA as well as psychometric properties of attitudes scales. International Journal of Science Education, 40(3), 268-290.

Thomson, S., \& Fleming, N. (2004). Summing it up: Mathematics achievement in Australian schools in TIMSS 2003. TIMSS Australia monograph no. 6. Camberwell, Australia: Australian Council for Educational Research.

Tuominen-Soini, H., Salmela-Aro, K., \& Niemivirta, M. (2011). Stability and change in achievement goal orientations: A person-centered approach. Contemporary Educational Psychology, 36(2), 82-100.

Weiner, B. (1992). Human motivation: Metaphors, theories, and research. Thousand Oaks, CA: Sage.

Wentzel, K. R., \& Wigfield, A. (2009). Handbook of motivation in school. New York, NY: Routledge.

Wigfield, A. (1994). Expectancy-value theory of achievement motivation: A developmental perspective. Educational Psychology Review, 6, 49-78.

Wigfield, A., \& Eccles, J. S. (1992). The development of achievement task values: A theoretical analysis. Developmental Review, 12(3), 265-310.

Wigfield, A., \& Eccles, J. (2002). The development of competence beliefs, expectancies for success, and achievement values from childhood through adolescence. In A. Wigfield, \& J. Eccles (Eds.), Development of achievement motivation (pp. 92-120). New York, NY: Academic Press.

Wigfield, A., Eccles, J. S., Mac Iver, D., Reuman, D. A., \& Midgley, C. (1991). Transitions during early adolescence: Changes in children's domain-specific self-perceptions and general selfesteem across the transition to junior high school. Developmental Psychology, 27(4), 552-565.

Winheller, S., Hattie, J., \& Brown, G. T. L. (2013). Factors influencing early adolescents' mathematics achievement: High-quality teaching rather than relationships. Learning Environments Research, 16(1), 49-69.

Open Access This chapter is licensed under the terms of the Creative Commons AttributionNonCommercial 4.0 International License (http://creativecommons.org/licenses/by-nc/4.0/), which permits any noncommercial use, sharing, adaptation, distribution and reproduction in any medium or format, as long as you give appropriate credit to the original author(s) and the source, provide a link to the Creative Commons license and indicate if changes were made.

The images or other third party material in this chapter are included in the chapter's Creative Commons license, unless indicated otherwise in a credit line to the material. If material is not included in the chapter's Creative Commons license and your intended use is not permitted by statutory regulation or exceeds the permitted use, you will need to obtain permission directly from the copyright holder. 